\title{
Elusive Identities and Overlapping Phenotypes of Proangiogenic Myeloid Cells in Tumors
}

\author{
Seth B. Coffelt, ${ }^{\star}$ Claire E. Lewis, ${ }^{*}$ Luigi Naldini, ${ }^{\dagger}$ \\ J. Martin Brown, ${ }^{\ddagger}$ Napoleone Ferrara, ${ }^{\S}$ \\ and Michele De Palma ${ }^{\dagger}$ \\ From the Academic Unit of Pathology," Medical School, University \\ of Sheffield, Sheffield, United Kingdom; the Angiogenesis and Tumor \\ Targeting Research Unit, ${ }^{\dagger}$ and HSR-TIGET, San Raffaele Scientific \\ Institute, and Vita-Salute San Raffaele University Medical School - \\ via Olgettina, Milan, Italy; the Department of Radiation Oncology, \\ Stanford University School of Medicine, Stanford, California; and \\ Genentech, Inc., ${ }^{\S}$ South San Francisco, California
}

It is now established that bone marrow-derived myeloid cells regulate tumor angiogenesis. This was originally inferred from studies of human tumor biopsies in which a positive correlation was seen between the number of tumor-infiltrating myeloid cells, such as macrophages and neutrophils, and tumor microvessel density. However, unequivocal evidence was only provided once mouse models were used to examine the effects on tumor angiogenesis by genetically or pharmacologically targeting myeloid cells. Since then, identifying the exact myeloid cell types involved in this process has proved challenging because of myeloid cell heterogeneity and the expression of overlapping phenotypic markers in tumors. As a result, investigators often simply refer to them now as "bone marrow-derived myeloid cells." Here we review the findings of various attempts to phenotype the myeloid cells involved and discuss the therapeutic implications of correctly identifyingand thus being able to target-this proangiogenic force in tumors. (Am J Pathol 2010, 176:1564-1576; DOI: 10.2353/ajpath.2010.090786)

There is now compelling evidence that bone marrowderived cells (BMDCs) play an important role in regulating angiogenesis during tumor progression and recovery after antiangiogenic or cytotoxic therapy. Myeloid-lineage BMDCs shown to be 'proangiogenic' in mouse tumor studies include monocytes/macrophages, ${ }^{1-7}$ dendritic cell (DC) precursors, ${ }^{8,9}$ mast cells, ${ }^{10,11}$ neutrophils, ${ }^{12-14}$ and the so-called 'myeloid-derived sup- pressor cells' (MDSCs, or CD11 $\mathrm{b}^{+} \mathrm{Gr}-1^{+}$cells). ${ }^{15-17}$ Such cells (see Table 12,3,5,9,15,16,18-31 for a glossary) are thought to promote angiogenesis in tumors largely by expressing factors that promote the growth and expansion of new blood vessels from the pre-existing vasculature - either by the direct stimulation of endothelial cells (ECs) or the remodeling of the extracellular matrix (reviewed in 32-37).

As will be seen, various experimental approaches have been used in mice to define the role of myeloid cells in tumor angiogenesis including their genetic manipulation or pharmacological targeting, sometimes in combination with BM transplantation (BMT). However, identifying the exact myeloid cell types involved in tumor angiogenesis is proving increasingly difficult, not only because considerable heterogeneity and functional redundancy exist among tumor-infiltrating myeloid cells, but also because these cell types often express overlapping phenotypic markers (Figure 1). In this review, we discuss the advantages and limitations of using different techniques and various markers to identify myeloid cells implicated in tumor angiogenesis as well as evaluate what they tell us about the identity and function of the cells involved.

In addition to 'classic' myeloid cells, other BMDCs have been implicated in tumor angiogenesis. These include various progenitor or precursor cell populations, such as hematopoietic stem/progenitor cells (HS/ PCs), ${ }^{38,39}$ endothelial progenitor cells (EPCs), 6,38,40-44 pericyte precursor cells, ${ }^{2,45,46}$ and mesenchymal stem/ stromal cells. ${ }^{47,48}$ The many unresolved issues related to

Supported by the Breast Cancer Campaign and Yorkshire Cancer Research, UK (to S.B.C. and C.E.L.), Associazione Italiana per la Ricerca sul Cancro (AIRC) and the European Union (FP6 Tumor-Host Genomics; to L.N. and M.D.P.), and NIH grant RO1 CA128873 (to J.M.B.).

Accepted for publication October 15, 2009.

Address reprint requests to Claire E. Lewis, Ph.D., Academic Unit of Pathology, Medical School, University of Sheffield, Beech Hill Road, Sheffield, S10 2RX, UK; or Michele De Palma, Ph.D., Angiogenesis and Tumor Targeting Research Unit, and HSR-TIGET, San Raffaele Scientific Institute, and Vita-Salute San Raffaele University Medical School via Olgettina, 58, 20132 Milan, Italy. E-mail: claire.lewis@sheffield. ac.uk or depalma.michele@hsr.it. 
Table 1. A Glossary for BMDCs Implicated in Tumor Angiogenesis

\begin{tabular}{|c|c|c|}
\hline $\begin{array}{c}\text { Definition } \\
\text { (alphabetic order) }\end{array}$ & Description & $\begin{array}{l}\text { References } \\
\text { (selected) }\end{array}$ \\
\hline CD11b ${ }^{+}$Gr- $1^{+}$cells & $\begin{array}{l}\text { CD11b and Gr-1 are cell surface markers broadly expressed by myeloid-lineage cells. } \\
\text { The combination of such markers is commonly used to identify a myeloid cell population } \\
\text { that expands in the bone marrow, blood, and spleen of tumor-bearing mice. The } \\
\text { CD } 11 \mathrm{~b}^{+} \mathrm{Gr}-1^{+} \text {cells comprise both monocyte- and granulocyte-lineage cells and are } \\
\text { also referred to as myeloid-derived suppressor cells (MDSCs). In tumors, CD } 11 \mathrm{~b}^{+} \mathrm{Gr}-1^{+} \\
\text {cells are less abundant than classic macrophages (which are } \mathrm{Gr}-1^{-} \text {) and mostly } \\
\text { comprise neutrophils and inflammatory monocytes. CD } 11 \mathrm{~b}^{+} \mathrm{Gr}-1^{+} \text {cells/MDSCs are } \\
\text { thought to promote tumor progression mainly through immunosuppression; however, } \\
\text { subsets of these cells-neutrophils in particular-may also promote angiogenesis via } \\
\text { both VEGF-dependent and independent pathways. }\end{array}$ & $15,16,18,19$ \\
\hline $\begin{array}{r}\text { Inflammatory } \\
\text { monocytes }\end{array}$ & $\begin{array}{l}\text { In the mouse, circulating monocytes can be separated into at least two main subsets: } \\
\text { inflammatory (or classic) and resident monocytes. Inflammatory monocytes are } \\
\text { considered the precursors of macrophages and dendritic cells recruited to inflamed } \\
\text { tissues (including tumors); they express Ly6C and CCR2, the receptor for CCL2 (also } \\
\text { known as monocyte chemoattractant protein-1, MCP-1). Once recruited to tumors, } \\
\text { inflammatory monocytes are thought to differentiate into tumor-associated macrophages } \\
\text { (TAMs). }\end{array}$ & $20-22$ \\
\hline Hemangiocytes & $\begin{array}{l}\text { The term "hemangiocyte" was coined by Rafii and coworkers to designate a population of } \\
\text { hematopoietic progenitors that express CD11b, VEGFR-1, CXCR4, Sca1, and Tie2. The } \\
\text { relationship between these hemangiocytes and other hematopoietic progenitors or } \\
\text { differentiated myeloid-lineage cells (such as monocytes, TEMs in particular) requires } \\
\text { further investigation. VEGFR- } 1^{+} \text {hemangiocytes and Tie } 2^{+} \text {monocytes appear to be a } \\
\text { major source of functional MMP9 in tumors. }\end{array}$ & 2 \\
\hline $\begin{array}{l}\text { M1 or classic } \\
\text { macrophage } \\
\text { activation }\end{array}$ & $\begin{array}{l}\text { In response to microbial agents and Th1 cytokines such as interferon- } \gamma \text {, macrophages } \\
\text { undergo an activation program referred to as "classic," or "M1" activation. Classically } \\
\text { activated macrophages are potent effector cells that can kill microorganisms and tumor } \\
\text { cells and produce copious amounts of proinflammatory cytokines. In vitro-polarized M1 } \\
\text { macrophages express high amounts of the antiangiogenic cytokines IL-12, CXCL9, and } \\
\text { CXCL10. }\end{array}$ & 23,24 \\
\hline $\begin{array}{l}\text { M2 or alternative } \\
\text { macrophage } \\
\text { activation }\end{array}$ & $\begin{array}{l}\text { Available information suggests that several tumor- and T cell-derived cytokines, such as } \\
\text { IL-4, IL-13, IL-10, as well as glucocorticoid hormones and vitamin D3, can induce TAMs } \\
\text { to undergo an "alternative" or "M2" activation program. M2-polarized macrophages } \\
\text { produce a variety of growth factors that regulate tumor-cell proliferation and invasion, } \\
\text { angiogenesis, and the deposition and dissolution of connective tissues. These include } \\
\text { epidermal growth factor (EGF), members of the fibroblast growth factor (FGF) and } \\
\text { vascular endothelial growth factor (VEGF) families, and transforming growth factor- } \beta \\
\text { (TGF- } \beta \text { ). It is generally believed that M2-polarized macrophages have a key role in } \\
\text { promoting tumor growth and progression and subverting antitumor immunity. It is likely } \\
\text { that fully polarized M1 and M2 macrophages are the extremes of a continuum of } \\
\text { phenotypes variably expressed in different tumor microenvironments (see Figure 2). }\end{array}$ & $19,23,24$ \\
\hline $\begin{array}{l}\text { MDSCs (myeloid- } \\
\text { derived } \\
\text { suppressor cells) }\end{array}$ & See CD $11 b^{+}$Gr-1+ cells. & \\
\hline Resident monocytes & $\begin{array}{l}\text { Circulating resident monocytes are a monocyte subpopulation distinct from inflammatory } \\
\text { monocytes. Resident monocytes, which are Ly6C } \mathrm{C}^{-} \text {and } C \mathrm{CR} 2^{-} \text {, patrol blood vessels } \\
\text { and may differentiate into proangiogenic macrophages once extravasated at sites of } \\
\text { tissue injury or ischemia. TEMs appear to be a subpopulation of resident monocytes; } \\
\text { the role of resident monocytes in tumors is otherwise very poorly known. }\end{array}$ & $20-22$ \\
\hline $\begin{array}{l}\text { TEMs (Tie2- } \\
\text { expressing } \\
\text { monocytes/ } \\
\text { macrophages) }\end{array}$ & $\begin{array}{l}\text { TEMs express the angiopoietin receptor Tie2, a feature that distinguishes them from other } \\
\text { monocytes/myeloid cells. TEMs circulate both in human and mouse peripheral blood } \\
\text { and are recruited to sites of tissue remodeling, including tumors, where they appear to } \\
\text { provide paracrine support to angiogenesis. }\end{array}$ & $5,25-27$ \\
\hline $\begin{array}{l}\text { TAMs (tumor- } \\
\text { associated } \\
\text { macrophages) }\end{array}$ & $\begin{array}{l}\text { TAMs are thought to derive from circulating inflammatory monocytes. F4/80 } 0^{+} \text {TAMs make } \\
\text { up a major proportion of the CD11 } \mathrm{b}^{+} \text {myeloid cells found in a variety of mouse tumor } \\
\text { models. Defined factors present in the tumor microenvironment can induce TAMs to } \\
\text { acquire distinct activation states (see M1 and M2 activation). In progressing tumors, } \\
\text { TAMs are largely M2-polarized and produce a wide array of proangiogenic factors. }\end{array}$ & $3,28,29$ \\
\hline Vascular leukocytes & $\begin{array}{l}\text { These cells represent a population of proangiogenic monocytes that coexpress myeloid } \\
\text { (eg, CD11b) and EC markers (eg, VE-Cadherin and Tie2). Vascular leukocytes are } \\
\text { particularly abundant in human ovarian cancers but are also detected in a number of } \\
\text { murine tumors. Recently, vascular leukocytes have been shown to phenotypically } \\
\text { overlap with TEMs. }\end{array}$ & $9,30,31$ \\
\hline
\end{tabular}

the phenotypic and functional identification of some of these progenitor/precursor cells-EPCs, in particular-in the context of tumor angiogenesis have stimulated a long-standing lively debate in the vascular biology field (reviewed in 33,49-53). The functional importance of EPCs in tumor angiogenesis has been discussed elsewhere (see references above) and is beyond the remit of this article. 


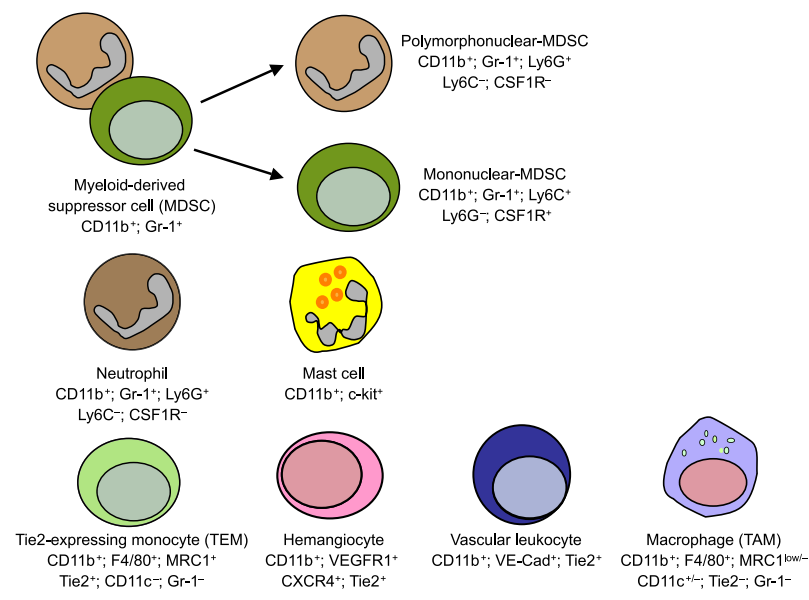

Figure 1. Various myeloid-lineage cell types implicated to date in the regulation of tumor angiogenesis. Markers expressed (or not expressed) by each of the distinct cell types are indicated. Note that several markers are coexpressed by different myeloid cell types, raising the question of whether some of these represent distinct cell types, rather then overlapping cell subsets or differentiation states of a same cell type.

\section{Myeloid Cells Implicated in Tumor Angiogenesis}

\section{Monocytes/Macrophages}

These cells are released from the bone marrow as promonocytes, mature into monocytes in the circulation, infiltrate tumors, and differentiate further into tumor-associated macrophages (TAMs). ${ }^{23,28}$ Once resident in tumors, macrophages express a wide array of proangiogenic factors, including vascular endothelial growth factor (VEGF)-A and matrix metalloproteinase (MMP) - 9. ${ }^{12,54,55}$ Evidence for their role in tumor angiogenesis has been established by several different experimental approaches. First, the combination of human macrophages and small avascular human tumor nodules implanted into a murine skinfold window chamber assay results in a significant increase in new blood vessels when compared with tumor nodules containing no macrophages. ${ }^{7}$ By using MMTV-PyMT mammary tumor-prone mice carrying a colony stimulating factor-1 (Csf1) null mutation (Csf1 ${ }^{\text {Op/op }}$ ), Lin and co-workers ${ }^{3,4}$ demonstrated that the absence of CSF-1 markedly decreased macrophage infiltration in pre-malignant tumors, and this, in turn, resulted in inhibition of tumor angiogenesis and delayed metastasis. Furthermore, inhibition of tumor-derived TAM chemoattractants, ablation of TAMs by DNA vaccination, or pharmacological neutralization of TAMproduced proangiogenic molecules also impaired tumor angiogenesis in various tumor models. ${ }^{56-58}$ It should be noted, however, that in Ccr2-deficient, K14-HPV cervical tumor-prone mice, the genetic depletion of TAMs unleashed a compensatory neutrophil response that rescued tumor angiogenesis and progression. ${ }^{14}$ This interesting observation highlights that a certain degree of functional redundancy exists among tumor-infiltrating proangiogenic myeloid cells and that this may vary in a tissue- or organ-specific fashion.

TAM depletion from tumors removes each of the many aspects of macrophage involvement from tumor progression. These include, in addition to the production of
VEGF-A and other proangiogenic factors, the release of cellular mediators that promote immunosuppression and enhance tumor cell survival, migration, and invasion. ${ }^{23,28,29,59}$ To specifically analyze the role of myeloid cell-derived VEGF-A in tumor angiogenesis, Stockmann and coworkers $^{60}$ crossed mice carrying loxP-flanked Vegfa alleles to mice carrying a lysozyme $M$ (LysM) promoter-driven Cre recombinase. Interestingly, the authors found that the targeted deletion of VEGF-A in myeloid cells failed to inhibit angiogenesis and tumor growth or decrease the overall amount of VEGF-A expressed in tumors. Rather, it attenuated the vascular abnormalities commonly observed in tumors and improved tumor perfusion (a phenomenon previously referred to as 'vascular normalization'61). These results suggest that VEGF-A production by TAMs promotes the formation of chaotic, poorly functional tumor-associated vasculature-at least in the murine tumor models used.

As defined here, TAMs comprise distinct macrophage subpopulations. Egeblad and coworkers ${ }^{62}$ developed and applied multicolor imaging techniques (reviewed in 63) to analyze the recruitment and behavior of macrophages and related myeloid cells in different tumor microenvironments in live mice. MMTV-PyMT mice were crossed with a transgenic mouse line expressing GFP under the control of the promoter of the Csf1r gene, which is specifically expressed in monocyte/macrophage-lineage cells. The movement of GFP+ cells within tumors was then visualized along with fluorescently labeled dextran (to label blood vessels and macrophages that engulf dextran) and fluorescently labeled monoclonal antibodies (to better identify the myeloid cell subsets involved). Based on their motility, expression of surface markers (such as mannose receptor-1, Mrc1/CD206), and ability to phagocytize dextran, the macrophages could be classified into distinct subpopulations, including low-migratory Mrc1+/dextran+ macrophages, which are found in the peritumor areas, and sessile Mrc1-/dextran- macrophages, which are found within the tumor mass. ${ }^{62}$ This real-time analysis of myeloid cell location, behavior, and gene expression within intact live tumors showed that the functional heterogeneity of tumor-infiltrating myeloid cells-macrophages in particular-may be greater than anticipated by the analysis of static markers on fixed tissues. In this regard, a recent study identified a distinct macrophage subpopulation that mediates metastatic cancer cell extravasation and pulmonary seeding in mouse tumor models. ${ }^{64}$

Several recent reports have shown that both mouse and human monocytes can be grouped into different functional subsets. In murine blood, these include 'inflammatory' monocytes, which can give rise to several subsets of macrophages (possibly including TAMs) and DCs under inflammatory conditions; as well as 'resident' monocytes, which appear to patrol blood vessels and promote tissue remodeling, and vascular healing, possibly by differentiating toward tissue-resident proangiogenic macrophages. ${ }^{20-22,65}$ One particular subset of circulating monocytes, the Tie2-expressing monocytes (TEMs), has been shown recently to play an important role in tumor angiogenesis. ${ }^{5,6,37}$ TEMs express the an- 


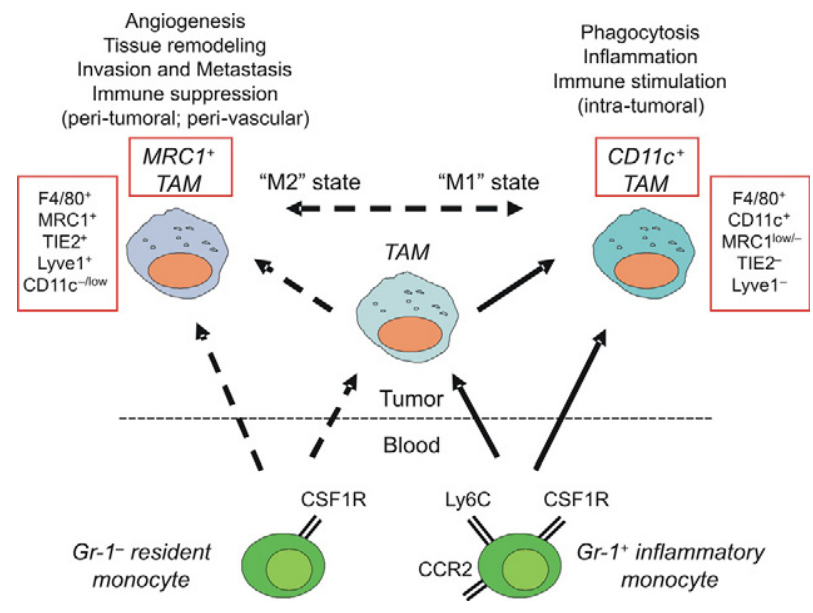

Figure 2. A schematic illustrating the possible relationships among monocyte/macrophage subpopulations found in tumors. Tumor-infiltrating macrophages are known to derive from circulating CCR2+ inflammatory monocytes; however, it remains to be investigated whether inflammatory monocytes give raise to each of the distinct macrophage subpopulations found in tumors. The contribution of CCR2-resident monocytes to tumor macrophages is currently unknown. Dashed arrows indicate putative developmental relationships.

giopoietin receptor Tie2, ${ }^{66}$ along with a wide array of monocyte/macrophage markers. Another monocytic cell type recently implicated in angiogenesis is the so-called 'vascular leukocyte.' ${ }^{30}$ These cells, which are particularly abundant in human ovarian tumors, coexpress monocyte and EC markers, including Tie2, suggesting their close relationship with TEMs. ${ }^{31}$

The developmental relationships among the distinct monocyte subsets and tumor-infiltrating macrophages are poorly defined (Figure 2). Monocytes are highly plastic cells, and it is generally believed that their intratumoral differentiation toward distinct macrophage subpopulations is regulated by the contextual assortment of cytokines, chemokines, and growth factors present in the tumor microenvironment. For instance, interleukin (IL)-4, $\mathrm{IL}-13$, and $\mathrm{IL}-10$ are thought to directly stimulate the growth-promoting and proangiogenic functions of TAMs, a process known as 'alternative macrophage activation' or 'M2 polarization' (reviewed in 24). However, it is also possible that distinct monocyte subsets give rise to distinct macrophage subpopulations in tumors. In line with this hypothesis, Pucci and coworkers ${ }^{25}$ suggested that circulating inflammatory and resident monocytes might give rise to two distinct $\mathrm{F} 4 / 80^{+}$tumor macrophage sub-

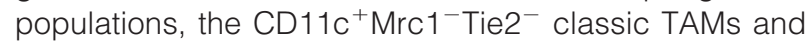

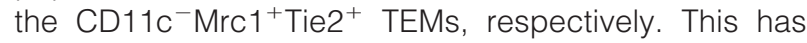
been inferred primarily by the observation that resident monocytes isolated from the blood of tumor-free mice display a gene expression profile that is more similar to tumor-derived TEMs than classic TAMs, whereas inflammatory monocytes are more closely related to TAMs than TEMs. These novel findings might suggest that distinct monocyte subsets are precommitted to distinct fates in the tumor microenvironment. ${ }^{25}$ Whether the different monocyte/macrophage subsets found in tumors represent distinct lineages ${ }^{25}$ or more plastic differentiation states, ${ }^{24}$ and whether they are related to each other by a precursor-to-mature cell relationship, is the object of current investigations.

\section{Polymorphonuclear Cells}

Granulocytes, neutrophils in particular, and mast cells are regarded a key source of proangiogenic factors in certain experimental tumors. An early study examining the importance of MMP9 and VEGF-A in pancreatic tumors of RIP1-Tag2 mice noted that inflammatory cells are the main producers of these two proangiogenic molecules in tumors. ${ }^{67}$ Neutrophils, together with monocytes/ macrophages, have since been identified as the predominant source of MMP9 and other proangiogenic molecules in RIP1-Tag2 mice. ${ }^{12,13}$ Although neutrophils are found in lower frequency than macrophages in RIP1Tag2 insulinomas, their elimination by means of anti-Gr-1 antibodies (which, however, also bind inflammatory monocytes; see below) in this tumor model reduces the levels of MMP9 in the tumors, which in turn inhibits the association of VEGF with VEGF receptor-2 (VEGFR-2) on ECs, thus suppressing angiogenesis. Interestingly, a recent study showed that neutrophils can either express a protumoral or antitumoral phenotype according to the levels of transforming growth factor (TGF)- $\beta$ present in the tumor. ${ }^{68}$ Indeed, TGF- $\beta$ blockade enhanced the recruitment of neutrophils with cytotoxic properties and inhibited the growth of transplanted tumors. Of note, the specific depletion of these neutrophils by means of antiLy6G antibodies rescued tumor growth. Thus, like TAMs, ${ }^{24}$ neutrophils may sense the tumor microenvironment and express different activation states, which determine their protumoral versus antitumoral activity in tumors. The antitumor activities of cytoxic neutrophils include the expression of immuno-activating cytokines and enhanced capability of killing tumor cells in vitro ${ }^{68}$; it will be worth investigating whether these "cytotoxic" neutrophils also display enhanced expression of antiangiogenic cytokines (or lower expression of proangiogenic ones) as compared with their "normal" counterpart.

MDSCs, often referred to as 'CD11b+Gr-1+ cells,' are a heterogeneous population of myeloid cells that encompasses immature monocytes, granulocytes, DCs, and their precursors. Their multifaceted function in tumors, phenotype, and complexity has been recently reviewed. ${ }^{18,19,69}$ The defining characteristics of MDSCs are largely based on their ability to suppress innate and adaptive immunity and expression of CD11b and Gr-1, whereas expression of other phenotypic markers by MDSCs varies because of their diversity and inclusion of myeloid cells at various stages of differentiation. Recent attempts at narrowing down specific subpopulations of these cells conclude that this group of cells can be divided into monocytic (mononuclear-MDSCs) and neutrophilic (polymorphonuclear-MDSCs) and DC subpopulations, which express phenotypic markers characteristic of each respective subset. ${ }^{70-73}$ There is also some evidence indicating that these subsets may have different functions in tumors, ${ }^{70}$ but the predominant phenotype and differentiation status of these cells once they migrate 
into premalignant tissue and tumors is unclear and is likely dependent on the tumor model and tumor type. Although MDSCs are believed to promote tumor progression through immunosuppression and other mechanisms, these cells (or subsets of them, such as neutrophils) may also influence angiogenesis ${ }^{15-17,69}$ _an effect mediated, at least in part, by their release of proangiogenic factors. In this regard, Shojaei and coworkers ${ }^{16}$ found that tumor refractoriness to anti-VEGF therapy correlates with the marked accumulation of $\mathrm{CD} 11 \mathrm{~b}^{+} \mathrm{Gr}-1^{+}$ myeloid cells (possibly neutrophils) within certain mouse tumors. This finding suggests that some tumors may co-opt VEGF-independent proangiogenic programs that are executed by the tumor-infiltrating myeloid cells. Prokinecitin 2, also known as Bv8 (a VEGF-like proangiogenic factor), is upregulated in myeloid cells by tumor-derived granulocyte colony-stimulating factor and appears to be a major player in driving refractoriness (or resistance) to anti-VEGF therapy. ${ }^{17}$ Yet, an immunosuppressive function has not been conclusively demonstrated for the proangiogenic CD $11 \mathrm{~b}^{+} \mathrm{Gr}-1^{+}$cells, raising the question of whether or not they can truly be referred to as MDSCs.

A number of experimental animal models have shown mast cells to be important for tumor angiogenesis. ${ }^{74}$ Mast cells accumulate during the premalignant stages of tumor progression and at the periphery of invasive tumors. They have direct proangiogenic activity attributable to their production of MMPs, particularly MMP-9, and secretion of other proangiogenic molecules such as basic fibroblast growth factor, VEGF, and IL-8. In addition, mast cells indirectly stimulate angiogenesis by secreting mast cell-specific serine proteases that activate pro-MMPs and stimulate stromal fibroblasts to synthesize collagens. ${ }^{36}$ Tumors grown in transgenic mice deficient in mast cells exhibit delayed tumor vascularization and progression. For instance, premalignant angiogenesis is abated in a mast cell-deficient skin tumor-prone K14-HPV transgenic mouse, ${ }^{10}$ as well as during pancreatic islet cell carcinogenesis, ${ }^{11}$ melanoma progression, ${ }^{75}$ and adenomatous colon polyposis. ${ }^{76}$

\section{BM Transplantation in the Study of Tumor Angiogenesis}

A number of studies have used myeloablative BMT to investigate the role of BM-derived myeloid cell in tumor angiogenesis. In the majority of such studies, transgenic mice ubiquitously expressing the reporter gene (eg, GFP or LacZ) are used as BM donors so the fate of their BM-derived cells after BMT can readily be identified and tracked in recipients. Such reports consistently document the accumulation of gene-marked myeloid-lineage BMDCs in tumors, but whether these cells represented monocytes, macrophages, mast cells, neutrophils, or other cell types (including hematopoietic progenitors) has often been ignored or not assessed in detail. In some studies, such gene-marking strategies have been combined with the use of cell type-specific antibodies on tumor sections in an attempt to identify distinct BMDC subsets in tumors (Table 2). 1,2,5,6,25 These have shown the presence of macrophages, monocytes, and granulocytes among the transplanted BM-derived cells in tumors. It should be noted, however, that ubiquitously expressed transgenes (such as those regulated by the Rosa26 locus or CMV/ $\beta$-actin promoter) may preclude the correct identification of each of the different BMDC types that are recruited to the tumor microenvironment. Indeed, transgene-positive macrophages, which massively infiltrate tumors, may mask the less abundant BMDC cell types and also increase the likelihood of detecting artifactual marking of nontransgenic cell types in the tumors. ${ }^{33}$ Mouse lines expressing transgenes under the control of myeloid-specific transcription regulatory elements (reviewed in 77) have been used to specifically label or deplete myeloid-lineage cells in mice. However, while narrowing down the range of BMDCs that express the transgene in blood and tumors, these transgenic mice may not always provide adequate resolution of the different myeloid BMDC types recruited to the tumors. Indeed, many of the "myeloid-specific" promoters (eg, the LysM, Csf1r, CD11c promoters) are broadly active among myeloid-lineage cells.

Regardless of the precise identity of the cell types involved, several reports have demonstrated the importance of BMDCs in tumor angiogenesis by transplanting wild-type BM cells into angiogenesis defective and/or tumor-resistant mice. ${ }^{1,5,6,38,42,55,78,79}$ In this setting, donor-derived BMDCs were able to rescue, at least in part, tumor angiogenesis and growth in the mutant mice. Different mechanisms have been proposed that may account for the ability of BMDCs to rescue the genetically hampered angiogenesis; these include the paracrine support of angiogenesis (via the release of proangiogenic factors) or the direct incorporation of the BMDCs in the tumor vasculature-the latter mechanism likely representing a very rare event. ${ }^{33}$ Coussens and coworkers used a BMT strategy to demonstrate that the expression of MMP9 by BMDCs is crucial for tumor angiogenesis and progression in the K14-HPV skin tumor-prone mice ${ }^{55}$ - a finding confirmed by further BMT studies in other mouse tumor models. ${ }^{1,2} \mathrm{Du}$ and coworkers ${ }^{2}$ studied the recruitment of several BMDC types, including EPCs, pericyte precursor cells, and distinct myeloid cell subsets $\left(\mathrm{CD} 11 \mathrm{~b}^{+}\right.$or VEGFR-1 ${ }^{+}$myeloid cells, F4/80 macrophages, and TEMs), to glioblastomas grown intracranially in mice previously transplanted with GFPtagged BM cells. The authors found that glioblastomas unable to express hypoxia inducible factor (HIF)- $1 \alpha$ recruit far fewer of these BMDCs and are severely impaired in their angiogenic phenotype and growth capacity. Indeed, in agreement with previous studies, ${ }^{80,81} \mathrm{HIF}-1 \alpha$ expressed in the highly hypoxic glioblastomas up-regulates the expression of both VEGF and stromal cellderived factor-1 (SDF-1, or CXCL12), which in turn promote the influx and retention of the various BMDCs in the tumor microenvironment. ${ }^{2}$ Among the tumor-infiltrating BMDCs, TEMs were found to be an important source of 
MMP9, possibly explaining why their impaired recruitment in HIF- $1 \alpha$-deficient tumors ${ }^{2}$ or genetic elimination in wild-type tumors ${ }^{5}$ impair angiogenesis and tumor growth. Chan and coworkers ${ }^{82}$ recently showed that knockdown of prolyl hyroxylase 2 (PHD2) - a molecular oxygen sensor and negative regulator of HIF- $\alpha$ subunits-in human colon carcinoma xenografts increases the number of tumor-associated $\mathrm{CD} 45^{+}$and $\mathrm{CD} 11 \mathrm{~b}^{+}$ cells and promotes angiogenesis. However, unlike the findings of Du and coworkers, ${ }^{2}$ they found that BMDC recruitment to tumors is HIF-independent. Indeed, PHD2 deficiency up-regulated the expression of the proangiogenic factors, IL-8, and angiogenin, in a NF$\kappa \mathrm{B}$-dependent but HIF-independent manner; IL-8 and angiogenin were found to be important both for the recruitment of BMDCs and the direct stimulation of angiogenesis. ${ }^{82}$ Regardless of precise mechanisms involved, these studies ${ }^{2,82}$ highlight the important role of tumor hypoxia for the recruitment of proangiogenic BMDCs to the tumor microenvironment.

BMT studies performed in various mouse tumor models have shown that TEMs play a crucial role in tumor angiogenesis. . $, 33,37,83$ TEMs were originally identified in the peripheral blood and tumors of mice transplanted with BM-derived HS/PCs transduced ex vivo with a lentiviral vector expressing GFP from Tie2 promoter/enhancer sequences. The generation of Tie2-GFP transgenic mice further confirmed that TEMs constitutively circulate in the mouse blood and preferentially extravasate in tumors and regenerating tissues. Importantly, TEMs have also been identified in human peripheral blood and cancer. ${ }^{31,26,27}$ When TEMs carrying a Tie2-driven suicide gene are selectively eliminated after BMT into tumor-bearing mice, tumor angiogenesis is inhibited and tumor growth markedly slowed; of note, the specific TEM elimination in tumor models does not affect the recruitment of other BMDCs, such as TAMs and neutrophils, to the tumors. ${ }^{5}$ TEMs differ from the bulk of $\mathrm{F} 4 / 80^{+}$ TAMs by their distinguishing gene signature and are enriched for genes that regulate tissue remodeling and angiogenesis. ${ }^{25}$

The BMT strategies described above show how the angiogenic program in tumors can be heavily modulated by the recruited BMDCs. However, BMT experiments usually use total body irradiation to enable the full engraftment of donor-derived cells in the recipient mice. In this regard, Ahn and Brown have shown that tissue irradiation may significantly affect the composition and proangiogenic activity of myeloid cell infiltrates in such tissues. ${ }^{1}$ Indeed, preirradiation of tissue before tumor cell inoculation enhances the recruitment of subsets of $\mathrm{BM}$-derived $\mathrm{CD} 11 \mathrm{~b}^{+}$myelomonocytic cells in the growing tumors. The enhanced recruitment of these $\mathrm{CD}_{11} \mathrm{~b}^{+}$cells at the site of tissue irradiation facilitates, or even rescues angiogenesis after radiationinduced EC damage. Indeed, the authors showed that newly recruited BMDCs represent the sole source of MMP9 in such irradiated tissues. In addition to the important role of BMDC-mediated MMP9 release in tumor angiogenesis, this study provides circumstantial evidence that tissue irradiation may alter the physiological fluxes of BMDCs to tumors.

Two recent reports have investigated the recruitment of BMDCs to the tumors of mice surgically joined by parabiosis. ${ }^{43,44}$ In these experiments, a GFP-transgenic mouse was surgically joined to a wild-type mouse to create a shared circulation between the two mice. The contribution of the circulating GFP-positive cells to tumor angiogenesis in the wild-type mouse was then studied without the need to myeloablate (ie, irradiate) the host hematopoietic system. In both studies, ${ }^{43,44}$ a variety of gene-marked BMDCs (mostly of the myelomonocytic lineage) were observed in the perivascular areas of both xenografted and spontaneous tumor models, with little evidence, if any, for the incorporation of bona fide EPCs in the tumor blood vessels. Although parabiotic mouse models seem to confirm BMT studies, it remains a possibility that irradiation and subsequent BMT make tumor angiogenesis more dependent on the paracrine support provided by BMDCs than in nonirradiated hosts.

\section{Phenotypic Markers Used to Identify Proangiogenic Myeloid Cells in Tumors}

As discussed above, to identify proangiogenic myeloid cells in murine tumors, investigators have used morphological criteria, examination of reporter gene expression, and/or assessment of various myeloid-related, phenotypic markers (see Table 2). ${ }^{1,2,5,6,25}$ However, as shown in Table 3 , the most common phenotypic markers used to dateCD45, CD11b, CD11C, F4/80, Gr-1, Tie2, CXCR4 and VEGFR-1 - are expressed by more than one myeloid cell type, making it difficult to distinguish one cell from another.

CD45 (leukocyte common antigen) is a transmembrane protein broadly expressed by hematopoietic-lineage cells, including myeloid and lymphoid cells. CD11b (also known as MAC-1) is generally regarded as only expressed by myeloid cells. However, several reports documented the expression of CD11b by lymphocyte and NK cell subsets, depending on their activation status. $^{84}$

Together with CD11b, F4/80 is a cell surface glycoprotein regularly used to identify murine TAMs ${ }^{85}$ Although broadly and robustly expressed by both tissue-resident and tumor-infiltrating macrophages, F4/80 expression level has been found to diminish with some forms of macrophage activation. ${ }^{86} \mathrm{It}$ is also expressed, albeit at lower levels, by circulating monocytes, ${ }^{20,21}$ mononuclearMDSCs, ${ }^{70-73}$ subpopulations of DCs, ${ }^{87}$ and peripheral blood eosinophils, ${ }^{88}$ so myeloid cells other than TAMs may express this antigen in tumors.

Markers/antigens expressed by neutrophils alone have proven extremely elusive. Ly6G is a surface molecule expressed almost exclusively on neutrophils and their precursors, and anti-Ly6G antibodies may thus provide a specific means to deplete these cells in mice. ${ }^{89}$ Another antibody used in many studies to identify or systemically deplete neutrophils in mice is anti-Gr-1, which however recognizes both Ly6C and Ly6G surface antigens. Thus, 
Table 2. A Summary of the Phenotypic Markers Used to Date to Determine the Contribution of BMDCs to Tumor Angiogenesis in Selected Publications

\begin{tabular}{cl} 
Reference & \multicolumn{1}{c}{ Mouse/tumor model used } \\
\hline 1 & MT1A2 murine mammary carcinoma or \\
& radiation-induced fibrosarcoma-in wild- \\
type mice, Mmp $^{-1-}$ mice, or Cd11b \\
promoter-driven diphtheria toxin receptor \\
(DTR)/GFP mice
\end{tabular}

6

5

25
TS/A and N202 mammary carcinoma, B16 melanoma, and Lewis lung carcinoma (LLC) cells inoculated into nude or syngenic C57BL/6 mice

Transgenic Tie2-GFP and Tie2-thymidine kinase (tk) FVB mice inoculated with N202 murine mammary cells; RIP1-Tag2 mice bearing orthotopic U87 human glioblastoma cells

Rag1-deficient (Rag1ko) and Rag1ko/ $\mathrm{Mmp9}^{-1-}$ mice inoculated with wild-type or HIF $1 \alpha$-deficient murine glioblastoma orthotopically

Transgenic Tie2-GFP FVB mice inoculated with N202 murine mammary cells; PyMTMMTV mammary tumor-prone mice spontaneous insulinoma model; nude
Experimental strategies (selected)

Transplantation of Tie2-LacZ or GFP-positive BM cells into pre-irradiated, tumor-bearing mice. Transplantation of wild-type BM cells into pre-irradiated, $\mathrm{Mmp9}^{-1-}$ tumor-bearing mice, also before treatment with zolendronic acid to target MMP9-expressing CD11b+ cells. Transplantation of Cd11b-DTR/GFP BM cells into Mmp- $9^{-1-}$ tumor-bearing mice before treatment with diphtheria toxin

Transplantation of lentiviral vector-transduced BM cells expressing GFP from Tie2 prom./ enh. or ubiquitous promoters (CMV; Pgk)into nude or immuno-competent tumorbearing mice. Transplantation of lentiviral vector-transduced BM cells expressing GFP and thymidine kinase from Tie2 prom./ enh. or ubiquitous promoter (Pgk)-before ganciclovir treatment of tumor-bearing mice to ablate TEMs or myeloid cells

Transplantation of Tie2-GFP-transduced BM into RIP1-Tag2 or U87 glioma-bearing mice Transplantation of Tie2-tk BM into N202 tumor-bearing FVB mice to ablate TEMs Transplantation of Tie2-tk BM into gliomabearing nude mice to ablate TEMs

Transplantation of GFP-positive Rag1ko or Rag1ko, Mmp9 ${ }^{-1-} \mathrm{BM}$ into Rag1ko or Rag1ko, $\mathrm{Mmp9}^{-1-}$ glioma-bearing mice

Transplantation of Tie2-GFP BM into PyMT-MMTV tumor-bearing mice
anti-Gr-1 antibodies not only bind $\mathrm{Ly}_{6 \mathrm{G}}{ }^{+}$neutrophils and their BM precursors, but also Ly6C ${ }^{+}$inflammatory monocytes, ${ }^{20,21} \mathrm{DCs}$, and T cell subsets. ${ }^{89}$ On the other hand, tumor-infiltrating TEMs and their circulating precursors are reported to be Gr-1-negative. ${ }^{5}$ As mentioned earlier, Gr-1 has also been used to help identify murine MDSCs (together with CD11b), so it cannot be used to distinguish between neutrophils and MDSCs.

Many markers once regarded as EC-specific (eg, VEGFR-1, Tie2, VE-Cadherin, and Sca-1) are also expressed by subsets of myeloid-lineage cells. VEGFR-1, a receptor activated by both VEGF-A and placental growth factor, is expressed by monocytes/macrophages and their progenitors in the hematopoietic system. ${ }^{90-92}$ The expression of the angiopoietin receptor, Tie2, ${ }^{66}$ has been reported on monocytes (TEMs), ${ }^{5}$ vascular leukocytes, ${ }^{31}$ and eosinophils, ${ }^{93}$ but not neutro- phils, ${ }^{5}$ mast cells, ${ }^{94}$ or MDSCs. ${ }^{70}$ Interestingly, vascular leukocytes have been shown to also express the EC-specific adhesion molecule, VE-Cadherin. ${ }^{9,30}$ It should be noted that Sca-1, which is often regarded as only expressed by HS/PCs and ECs, is now known to be more broadly expressed in the hematopoietic system, as both myeloid and lymphoid cell subsets may express this molecule. Similarly, the SDF-1 receptor CXCR4 is broadly, albeit not uniformly, expressed by murine hematopoietic cells. ${ }^{36}$ Thus, CD11b-, F4/80-, Tie2-, VEGFR-1-, and CXCR4-expressing myeloid cells, which have been reported to be proangiogenic in tumors by several studies, ${ }^{1,2,5,6,38}$ may well represent overlapping rather than distinct cell subsets.

Additional studies are now required to better understand the phenotypic and functional complexity of myelomonocytic cells found in tumors. As an example, Pucci 
Table 2. Continued

\begin{tabular}{|c|c|c|c|c|c|c|c|c|c|c|}
\hline \multirow[b]{2}{*}{$\begin{array}{l}\text { Myeloid cell(s) } \\
\text { Identified }\end{array}$} & \multicolumn{10}{|c|}{ Phenotypic markers expressed by myeloid cells in tumors after bone marrow transplantation } \\
\hline & CD45 & CD11b & $\mathrm{F} 4 / 80$ & Tie2 & Gr-1 & CXCR4 & VEGFR1 & VEGFR2 & CD34 & Other markers \\
\hline $\begin{array}{l}\text { BM-derived } \\
\text { myelomonocytic } \\
\text { cell }^{*}\end{array}$ & ND & + & ND & ND & - & ND & ND & ND & ND & CD11c ${ }^{-}$ \\
\hline $\begin{array}{l}\text { Tie2 }+ \text { cell } \\
\text { (BM-derived, } \\
\text { non-endothelial } \\
\text { cell) }\end{array}$ & ND & ND & ND & Tie2-LacZ+ & ND & ND & ND & ND & ND & CD31- \\
\hline $\begin{array}{l}\text { TEM } \\
\text { Macrophage } \\
\text { Granulocyte }\end{array}$ & $\begin{array}{l}+ \\
+ \\
+\end{array}$ & $\begin{array}{l}+ \\
+ \\
+\end{array}$ & $\begin{array}{l}+ \\
+ \\
-\end{array}$ & $\begin{array}{l}+ \\
- \\
-\end{array}$ & $\begin{array}{l}- \\
- \\
+\end{array}$ & $\begin{array}{l}\text { ND } \\
N D \\
N D\end{array}$ & $\begin{array}{l}\text { ND } \\
N D \\
N D\end{array}$ & $\begin{array}{l}- \\
N D \\
N D\end{array}$ & $\begin{array}{l}+/- \\
- \\
\mathrm{ND}\end{array}$ & $\begin{array}{l}\text { CD31- }{ }^{-} \text {Sca-1 } 1^{+} \\
\text {CD31- } \text { Sca }^{-} 1^{-} \\
\text {ND }\end{array}$ \\
\hline TEM & + & + & + & + & - & ND & ND & - & - & c-Kit ${ }^{-}$Sca-1 ${ }^{+}$ \\
\hline Macrophage & + & + & + & - & - & ND & ND & ND & ND & \\
\hline Granulocyte & + & ND & - & - & + & ND & ND & - & - & \\
\hline $\begin{array}{l}\text { Mesenchymal } \\
\text { progenitor } \\
\text { (non-BMDC) }\end{array}$ & - & - & - & + & - & ND & ND & ND & ND & $\begin{array}{l}\mathrm{CD} 13^{+}, \mathrm{CD} 31^{-}, \mathrm{Sca}-^{+} \\
{\mathrm{C}-\mathrm{Kit}^{+/-}}^{+}, \mathrm{CD} 45^{-}\end{array}$ \\
\hline Macrophage & + & ND & + & ND & ND & ND & ND & ND & ND & CD31- \\
\hline Myeloid cell & + & + & ND & ND & ND & ND & ND & ND & ND & CD31- \\
\hline TEM & + & ND & ND & + & ND & ND & ND & ND & ND & CD31- \\
\hline Hemangiocyte** & + & ND & ND & ND & ND & ND & + & ND & ND & CD31- \\
\hline $\mathrm{BMDC}^{\star \star \star *}$ & + & ND & ND & ND & ND & + & ND & ND & ND & CD31- \\
\hline $\begin{array}{l}\text { Pericyte progenitor } \\
\text { cell (PPC) }\end{array}$ & - & $-1+$ & - & ND & ND & ND & ND & ND & ND & $\begin{array}{l}\text { CD31- }{ }^{-}, \text {PDGFR- } \beta^{+}, \\
\text {Sca- } 1^{+}\end{array}$ \\
\hline TEM & + & + & + & + & - & ND & ND & ND & ND & 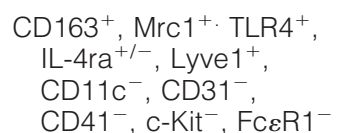 \\
\hline TAM & + & + & + & - & - & ND & ND & ND & ND & $\begin{array}{l}\text { CD11c }^{+}, \text {Lyve1 } 1^{-}, \mathrm{CD} 163^{-/+}, \\
\text {MRC1 }^{-1+}, \text { TLR4 }^{-}, \text {CD31 }^{-} \text {, } \\
\text { CD41 }\end{array}$ \\
\hline
\end{tabular}

+ indicates expressed/measured; -, not expressed; ND, not determined; BMDC, bone marrow-derived cell; TEM, Tie2-expressing monocyte.

*Includes subset of Tie2-expressing cells (TEMs).

**The term "hemangiocyte" has been coined by Rafii and colleagues (Jin et al., Nat Med 2006) to indicate a type of myeloid precursor cell expressing VEGFR1, CXCR4, Sca-1, and Tie2, in ischemic tissues.

${ }^{* *}$ The expression of CXCR4 and VEGFR1 has been previously associated with MMP9 ${ }^{+}$BMDCs recruited to heart and liver upon transgenic overexpression of VEGF (Grunewald et al., Cell 2006).

et al recently compared gene expression in TEMs and TAMs from murine tumors along with spleen-derived CD11b+Gr-1+ MDSCs. Although TEMs were highly related to TAMs (but not to MDSCs), several genes were found to be differentially expressed in the two macrophage subpopulations, suggesting that TEMs represent a distinct subset or differentiation state of TAMs. Among these, Arginase1 (Arg1) and many scavenger receptors were up-regulated, whereas Nos2 and many proinflammatory molecules were down-regulated in TEMs versus TAMs (Table 2). ${ }^{1,2,5,6,25}$ These data have helped identify a TEM surface marker profile $\left(\mathrm{F} 4 / 80^{+} \mathrm{Gr}-1^{-} \mathrm{Tie} 2^{+} \mathrm{Mrc} 1^{+}\right.$
CD11c ${ }^{\text {low } /-}$ CD $163^{+}$Lyve $^{+}{ }^{+} \mathrm{TLR}^{+}{ }^{+}$Stab $\left.1^{+}\right)$, which distinguishes them from the bulk of TAMs $\left(\mathrm{F} 4 / 80^{+} \mathrm{Gr}-1^{\mathrm{low} /-}\right.$

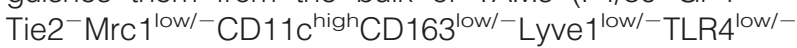
Stab1 $1^{\text {low/- }}$ ). Moreover, the data have identified molecular pathways that may account for the marked proangiogenic and protumoral activity of TEMs and might be targeted to block the activity of TEMs in tumors. ${ }^{25}$ Genome-wide expression profiling of the distinct myeloid cell types identified so far in tumors may unravel, together with live imaging analysis, ${ }^{62}$ novel and/or celltype specific markers that better address their phenotypic and functional relationships. 
Table 3. Overlapping Expression of Phenotypic Markers/Antigens by Individual Myeloid Cell Types

\begin{tabular}{|c|c|c|c|c|c|c|c|c|c|c|c|c|c|c|c|c|c|c|}
\hline \multirow[b]{2}{*}{ Marker } & \multicolumn{2}{|c|}{$\begin{array}{l}\text { Inflammatory } \\
\text { Monocyte }\end{array}$} & \multicolumn{2}{|c|}{$\begin{array}{l}\text { Resident } \\
\text { Monocyte }\end{array}$} & \multicolumn{2}{|c|}{ TAM } & \multicolumn{2}{|c|}{ TEM } & \multicolumn{2}{|c|}{$\begin{array}{l}\text { Dendritic } \\
\text { cell }\end{array}$} & \multicolumn{2}{|c|}{ Mast cell } & \multicolumn{2}{|c|}{ Neutrophil } & \multicolumn{2}{|c|}{ Eosinophil } & \multicolumn{2}{|c|}{ MDSC } \\
\hline & $M$ & $\mathrm{H}$ & $M$ & $\bar{H}$ & $M$ & $\bar{H}$ & $M$ & $\mathrm{H}$ & $M$ & $\bar{H}$ & $M$ & $\bar{H}$ & $\bar{M}$ & $\mathrm{H}$ & $\bar{M}$ & $\bar{H}$ & $M$ & $\mathrm{H}$ \\
\hline CD45 & + & + & + & + & + & + & + & + & + & + & + & + & + & + & + & + & + & + \\
\hline CD11b & + & + & + & + & + & + & + & + & + & + & + & + & + & + & + & + & + & + \\
\hline $\mathrm{F} 4 / 80^{*}$ & + & - & + & - & + & - & + & - & + & - & - & ND & - & - & $?$ & ND & $+1-$ & ND \\
\hline CD11c & $+1-$ & + & $+1-$ & + & $+1-$ & - & - & - & + & + & - & - & - & - & - & - & $+1-$ & ND \\
\hline Mrc1 & - llow & ND & + & ND & - llow & ND & + & ND & ND & ND & - & - & - & ND & - & - & ND & ND \\
\hline Tie2 & - & - llow & low & low & - & - & + & + & ND & ND & - & ND & - & $+1-$ & + & ND & - & ND \\
\hline $\mathrm{Gr} 1$ & + & $x$ & - & $x$ & - /low & $x$ & - & $x$ & low & $x$ & - & $x$ & + & $x$ & + & $x$ & + & $x$ \\
\hline CXCR4 & + & + & + & + & + & + & ND & ND & + & + & ND & + & + & + & + & + & + & ND \\
\hline VEGFR $1^{\dagger}$ & ND & ND & ND & ND & + & + & ND & ND & + & + & - & + & + & + & + & + & + & + \\
\hline
\end{tabular}

$\mathrm{M}$ indicates mouse; $\mathrm{H}$, human; +, expression of antigen has been confirmed; low, expression of antigen low or limited to a fraction of the cells; antigen not expressed $+/-$, positive expression reported by some investigators and negative expression by others; ND, not determined; $\mathrm{X}$, antigen does not exist for this species.

*The human homolog of murine F4/80 is known as "EGF-like module containing mucin-like hormone receptor (EMR)-1."

†VEGFR1 expression has been confirmed on monocytes, but it is not known whether expression levels are different between inflammatory and resident subsets.

\section{Relevance of BMDCs to Human Tumor Angiogenesis}

As mentioned earlier, a number of studies have reported significant correlations between the number of various myeloid cell types and microvessel density/angiogenesis in human tumors (reviewed recently in 32). However, similarities between the phenotype and function of the human tumor-infiltrating myeloid cell types and the proangiogenic BMDCs described earlier in mouse models have yet to be investigated. To date, human tumor studies have focused on just individual or small combinations of hematopoietic or myeloid cell markers. For example, increased numbers of $\mathrm{CD} 45^{+}$cells are associated with high microvessel density in some human tumor types. ${ }^{95,96} \mathrm{CD} 11 \mathrm{~b}^{+}$myeloid cells have been shown to be present in human tumors, ${ }^{27,97}$ but no studies to date have correlated their number or function with human tumor angiogenesis. Moreover, the Ly6C and Ly6G antigens are specific to the mouse, so the role of $\mathrm{Gr}-1^{+}$myeloid cells cannot be assessed in human tumors.

TAMs are usually identified in human tumors by their expression of $\mathrm{CD}^{2} 8^{23,54}$ rather than $\mathrm{F} 4 / 80$. Indeed, the human homolog of F4/80, the EGF-like module containing mucin-like hormone receptor-1, is expressed by eosinophils rather than monocytes or macrophages. ${ }^{98}$ Elevated numbers of $\mathrm{CD}^{+} 8^{+}$TAMs have been correlated with increased vascularization in human tumors. ${ }^{99}$ VEGFR-1 expression has also been reported on TAMs in tumors. ${ }^{100}$ Ruan and coworkers ${ }^{101}$ reported that aggressive human lymphoma subtypes recruit more $\mathrm{CD} 68^{+} \mathrm{VEGFR}-1^{+}$myeloid cells than indolent lymphomas. The CD68 ${ }^{+}$VEGFR-1 ${ }^{+}$ cells were localized around tumor blood vessels, as well as in the stromal compartment of the tumor; interestingly, these cells expressed VEGF-A, suggesting that a paracrine cross talk between myeloid cells and blood vessels occurs in aggressive lymphomas. Macrophages also express CXCR4 in human tumors and ascites fluid, ${ }^{102,103}$ whereas information regarding CXCR4 expression on other myeloid cell types in tumors is lacking.

Monocytes/macrophages expressing CD14, CD11b, and TIE2, likely corresponding to the human counterpart of murine TEMs, have also been detected in human tumor biopsies. $^{31,27}$ The human TEMs represent a minor proportion of the $\mathrm{CD} 45^{+}$tumor-infiltrating hematopoietic cells but appear to be highly proangiogenic as they promote tumor angiogenesis when coinjected with human tumor cells in immunodeficient mice. Although TIE2 expression has been reported on human peripheral blood neutrophils by some groups and not by others, ${ }^{26,27,104}$ the existence of tumor-associated TIE2 ${ }^{+}$ neutrophils has yet to be reported. Detailed colocalization studies are now warranted to see whether BMDCs expressing all or most of the markers expressed by proangiogenic BMDCs in murine tumors are present in human tumors-and whether their presence, number, or pattern of distribution positively correlates with tumor angiogenesis. The use of human/mouse chimera approaches, such as the reconstitution of the BM of immunodeficient mice with human HS/PCs, could provide an experimental tool to investigate the contribution of human BMDCs to angiogenesis in xenografted human tumors. Whereas these mouse models can be used to track the fate of transplanted human HS/PCs, they unfortunately only allow for limited human myelopoiesis and thus may fail to reliably assess the contribution of human myeloid cells to tumor angiogenesis.

\section{Concluding Remarks}

The studies discussed above show that identification of the distinct myeloid cell types responsible for driving tumor angiogenesis remains a major challenge at the present time. Not only do different myeloid cells exhibit overlapping markers, but the exact level and combination of these may alter as they differentiate and respond to local signals in their tissue microenvironment. A classic example of the latter is the heterogeneity of macrophage phenotypes seen in tumors. This may either reflect the existence of developmentally distinct subpopulations, or the influence of signals in the tumor microenvironment like hypoxia and/or various cytokines on a common monocyte precursor (or the combination of both). Moreover, the balance of these influences may differ between tumor types and indeed between tumors of a given type. 
The type and degree of myeloid cell infiltration into each tumor may vary depending on the specific BM-mobilizing and -recruiting factors released, as each tumor type mounts its own protumorigenic microenvironment. In this regard, it is generally believed that the type and concentration of cytokines and growth factors expressed in the tumor microenvironment may shape the phenotype and function of TAMs. This concept is exemplified by the macrophage polarization paradigm proposed by some authors. ${ }^{23,24}$ According to this, TAMs are driven by certain tumor- and $T$ cell-derived cytokines to acquire a polarized "M2" phenotype, which favors tissue remodeling, angiogenesis, and the suppression of antitumor immunity. Similarly, tumor-derived factors such as granulocyte colony-stimulating factor or TGF- $\beta$ may drive neutrophils to acquire protumoral and proangiogenic functions. ${ }^{13,17,68}$ This implies that neutralizing certain tumor-derived molecules may blunt the proangiogenic and protumoral activities of macrophages and neutrophils, possibly by skewing them toward and antitumoral phenotype. On the other hand, recent studies have suggested that, at least in certain murine tumors, only a specific subset of the infiltrating macrophages, the TEMs, display a profoundly "M2" skewed phenotype, whereas another subset of TAMs retains features of antigen-presenting cells and produces lower amounts of proangiogenic factors. ${ }^{25}$ These findings also suggest that distinct macrophage subpopulations (ie, the TEMs and TAMs) may arise from distinct circulating precursor cells.

Given the plethora of new studies uncovering such information about the ontogeny and diversity of myeloid cellsand how they are influenced by the tumor microenvironment-it remains to be seen whether future studies using cell markers alone will be able to unambiguously identify the major cell type(s) involved. As discussed above, it may take new approaches like the intravital imaging of myeloid cells in live murine tumors to clarify their functions in relation to the dynamic tumor microenvironment. ${ }^{62}$ Moreover, lineagespecific cell-tracking studies are needed to investigate the developmental relationships between BMDCs that traffic to tumors. For instance, by genetic labeling and then following of monocyte precursors, it may be possible to see whether distinct monocyte/macrophage subpopulations, such as the TEMs, TAMs, and "hemangiocytes," are derived from a single, circulating precursor cell or separate ones.

One outstanding question still needs to be addressed: is it possible to identify molecular targets that could distinguish proangiogenic protumoral myeloid cells from the antitumoral myeloid cells that regulate effective immune responses against the tumor? If future studies identify one or more cell surface proteins that are expressed by all proangiogenic myeloid cells in tumors, it is possible that they could be targeted by antibody-based or gene therapeutic methods. Such a 'broad-brush' approach may be important, as there is now evidence that selective deletion of just one proangiogenic myeloid cell type (eg, macrophages) from murine tumors may promote another proangiogenic one (like neutrophils) to take on the role of driving tumor angiogenesis. ${ }^{14,72}$ These strategies may also have implications for the efficacy of conventional therapies as such proangiogenic BMDCs have been implicated in the responses of murine tumors to radiation or chemotherapeutic agents. ${ }^{1,16,58}$ Alternatively, subpopulations of such proangiogenic myeloid cells like TEMs can be used to deliver gene therapy to sites of neovascularization in tumors. ${ }^{105}$

\section{References}

1. Ahn GO, Brown JM: Matrix metalloproteinase-9 is required for tumor vasculogenesis but not for angiogenesis: role of bone marrowderived myelomonocytic cells. Cancer Cell 2008, 13:193-205

2. Du R, Lu KV, Petritsch C, Liu P, Ganss R, Passegue E, Song H, Vandenberg S, Johnson RS, Werb Z, Bergers G: HIF1alpha induces the recruitment of bone marrow-derived vascular modulatory cells to regulate tumor angiogenesis and invasion. Cancer Cell 2008, 13:206-220

3. Lin EY, Li JF, Gnatovskiy L, Deng Y, Zhu L, Grzesik DA, Qian H, Xue XN, Pollard JW: Macrophages regulate the angiogenic switch in a mouse model of breast cancer. Cancer Res 2006, 66:11238-11246

4. Lin EY, Nguyen AV, Russell RG, Pollard JW: Colony-stimulating factor 1 promotes progression of mammary tumors to malignancy. J Exp Med 2001, 193:727-740

5. De Palma M, Venneri MA, Galli R, Sergi Sergi L, Politi LS, Sampaolesi M, Naldini L: Tie2 identifies a hematopoietic lineage of proangiogenic monocytes required for tumor vessel formation and a mesenchymal population of pericyte progenitors. Cancer Cell 2005 8:211-226

6. De Palma M, Venneri MA, Roca C, Naldini L: Targeting exogenous genes to tumor angiogenesis by transplantation of genetically modified hematopoietic stem cells. Nat Med 2003, 9:789-795

7. Bingle L, Lewis CE, Corke KP, Reed MW, Brown NJ: Macrophages promote angiogenesis in human breast tumour spheroids in vivo. Br J Cancer 2006, 94:101-107

8. Conejo-Garcia JR, Benencia F, Courreges MC, Kang E, MohamedHadley A, Buckanovich RJ, Holtz DO, Jenkins A, Na H, Zhang L, Wagner DS, Katsaros D, Caroll R, Coukos G: Tumor-infiltrating dendritic cell precursors recruited by a beta-defensin contribute to vasculogenesis under the influence of Vegf-A. Nat Med 2004, 10:950-958

9. Conejo-Garcia JR, Buckanovich RJ, Benencia F, Courreges MC, Rubin SC, Carroll RG, Coukos G: Vascular leukocytes contribute to tumor vascularization. Blood 2005, 105:679-681

10. Coussens LM, Raymond WW, Bergers G, Laig-Webster M, Behrendtsen O, Werb Z, Caughey GH, Hanahan D: Inflammatory mast cells up-regulate angiogenesis during squamous epithelial carcinogenesis. Genes Dev 1999, 13:1382-1397

11. Soucek L, Lawlor ER, Soto D, Shchors K, Swigart LB, Evan GI: Mast cells are required for angiogenesis and macroscopic expansion of Myc-induced pancreatic islet tumors. Nat Med 2007, 13:1211-1218

12. Nozawa $H$, Chiu $C$, Hanahan D: Infiltrating neutrophils mediate the initial angiogenic switch in a mouse model of multistage carcinogenesis. Proc Natl Acad Sci USA 2006, 103:12493-12498

13. Shojaei F, Singh M, Thompson JD, Ferrara N: Role of Bv8 in neutrophil-dependent angiogenesis in a transgenic model of cancer progression. Proc Natl Acad Sci USA 2008, 105:2640-2645

14. Pahler JC, Tazzyman S, Erez N, Chen YY, Murdoch C, Nozawa H, Lewis CE, Hanahan D: Plasticity in tumor-promoting inflammation: impairment of macrophage recruitment evokes a compensatory neutrophil response. Neoplasia 2008, 10:329-340

15. Yang L, DeBusk LM, Fukuda K, Fingleton B, Green-Jarvis B, Shyr Y, Matrisian LM, Carbone DP, Lin PC: Expansion of myeloid immune suppressor $\mathrm{Gr}+\mathrm{CD} 11 \mathrm{~b}+$ cells in tumor-bearing host directly promotes tumor angiogenesis. Cancer Cell 2004, 6:409-421

16. Shojaei F, Wu X, Malik AK, Zhong C, Baldwin ME, Schanz S, Fuh G Gerber HP, Ferrara N: Tumor refractoriness to anti-VEGF treatment is mediated by CD11b+Gr1+ myeloid cells. Nature Biotechnol 2007, 25:911-920

17. Shojaei F, Wu X, Zhong C, Yu L, Liang XH, Yao J, Blanchard D, Bais C, Peale FV, van Bruggen N, Ho C, Ross J, Tan M, Carano RA, Meng 
YG, Ferrara N: Bv8 regulates myeloid-cell-dependent tumour angiogenesis. Nature 2007, 450:825-831

18. Ostrand-Rosenberg S, Sinha P: Myeloid-derived suppressor cells: linking inflammation and cancer. J Immunol 2009, 182:4499-4506

19. Sica A, Bronte V: Altered macrophage differentiation and immune dysfunction in tumor development. J Clin Invest 2007, 117:1155-1166

20. Geissmann F, Jung S, Littman DR: Blood monocytes consist of two principal subsets with distinct migratory properties. Immunity 2003 19:71-82

21. Gordon S, Taylor PR: Monocyte and macrophage heterogeneity. Nat Rev Immunol 2005, 5:953-964

22. Auffray C, Fogg D, Garfa M, Elain G, Join-Lambert O, Kayal S, Sarnacki S, Cumano A, Lauvau G, Geissmann F: Monitoring of blood vessels and tissues by a population of monocytes with patrolling behavior. Science 2007, 317:666-670

23. Mantovani A, Allavena P, Sica A, Balkwill F: Cancer-related inflammation. Nature 2008, 454:436-444

24. Mantovani A, Sozzani S, Locati M, Allavena P, Sica A: Macrophage polarization: tumor-associated macrophages as a paradigm for polarized M2 mononuclear phagocytes. Trends Immunol 2002, 23:549-555

25. Pucci F, Venneri MA, Biziato D, Nonis A, Moi D, Sica A, Di Serio C, Naldini L, De Palma M: A distinguishing gene signature shared by tumor-infiltrating Tie2-expressing monocytes, blood "resident" monocytes, and embryonic macrophages suggests common functions and developmental relationships. Blood 2009, 114:901-914

26. Murdoch C, Tazzyman S, Webster S, Lewis CE: Expression of Tie-2 by human monocytes and their responses to angiopoietin-2. J Immunol 2007, 178:7405-7411

27. Venneri MA, De Palma M, Ponzoni M, Pucci F, Scielzo C, Zonari E, Mazzieri R, Doglioni C, Naldini L: Identification of proangiogenic TIE2-expressing monocytes (TEMs) in human peripheral blood and cancer. Blood 2007, 109:5276-5285

28. Lewis CE, Pollard JW: Distinct role of macrophages in different tumor microenvironments. Cancer Res 2006, 66:605-612

29. Condeelis J, Pollard JW: Macrophages: obligate partners for tumor cell migration, invasion, and metastasis. Cell 2006, 124:263-266

30. Balint K, Conejo-Garcia JR, Buckanovich R, Coukos G: Role of vascular leukocytes in ovarian cancer neovascularization. Adv Exp Med Biol 2008, 622:273-280

31. Pulaski HL, Spahlinger G, Silva IA, McLean K, Kueck AS, Reynolds RK, Coukos G, Conejo-Garcia JR, Buckanovich RJ: Identifying alemtuzumab as an anti-myeloid cell antiangiogenic therapy for the treatment of ovarian cancer. J Transl Med 2009, 7:49

32. Murdoch C, Muthana M, Coffelt SB, Lewis CE: The role of myeloid cells in the promotion of tumour angiogenesis. Nat Rev Cancer $2008,8: 618-631$

33. De Palma M, Naldini L: Role of haematopoietic cells and endothelial progenitors in tumour angiogenesis. Biochim Biophys Acta 2006, 1766:159-166

34. Lin EY, Pollard JW: Tumor-associated macrophages press the angiogenic switch in breast cancer. Cancer Res 2007, 67:5064-5066

35. Shojaei F, Zhong C, Wu X, Yu L, Ferrara N: Role of myeloid cells in tumor angiogenesis and growth. Trends Cell Biol 2008, 18:372-378

36. De Palma M, Coussens LM: Immune Cells and Inflammatory Mediators as Regulators of Tumor Angiogenesis. Angiogenesis: An integrative approach from science to medicine. Springer U.S. 2008, pp. 225-237

37. De Palma M, Murdoch C, Venneri MA, Naldini L, Lewis CE: Tie2expressing monocytes: regulation of tumor angiogenesis and therapeutic implications. Trends Immunol 2007, 28:519-524

38. Lyden D, Hattori K, Dias S, Costa C, Blaikie P, Butros L, Chadburn A, Heissig B, Marks W, Witte L, Wu Y, Hicklin D, Zhu Z, Hackett NR, Crystal RG, Moore MA, Hajjar KA, Manova K, Benezra R, Rafii S: Impaired recruitment of bone-marrow-derived endothelial and hematopoietic precursor cells blocks tumor angiogenesis and growth. Nat Med 2001, 7:1194-1201

39. Okamoto R, Ueno M, Yamada Y, Takahashi N, Sano H, Suda T, Takakura N: Hematopoietic cells regulate the angiogenic switch during tumorigenesis. Blood 2005, 105:2757-2763

40. Gothert JR, Gustin SE, van Eekelen JA, Schmidt U, Hall MA, Jane SM, Green AR, Gottgens B, Izon DJ, Begley CG: Genetically tagging endothelial cells in vivo: bone marrow-derived cells do not contribute to tumor endothelium. Blood 2004, 104:1769-1777
41. Nolan DJ, Ciarrocchi A, Mellick AS, Jaggi JS, Bambino K, Gupta S, Heikamp E, McDevitt MR, Scheinberg DA, Benezra R, Mittal V: Bone marrow-derived endothelial progenitor cells are a major determinant of nascent tumor neovascularization. Genes Dev 2007, 21:1546-1558

42. Shaked Y, Ciarrocchi A, Franco M, Lee CR, Man S, Cheung AM, Hicklin DJ, Chaplin D, Foster FS, Benezra R, Kerbel RS: Therapyinduced acute recruitment of circulating endothelial progenitor cells to tumors. Science 2006, 313:1785-1787

43. Purhonen S, Palm J, Rossi D, Kaskenpaa N, Rajantie I, Yla-Herttuala S, Alitalo K, Weissman IL, Salven P: Bone marrow-derived circulating endothelial precursors do not contribute to vascular endothelium and are not needed for tumor growth. Proc Natl Acad Sci USA 2008, 105:6620-6625

44. Kim SJ, Kim JS, Papadopoulos J, Wook Kim S, Maya M, Zhang F $\mathrm{He} \mathrm{J}$, Fan D, Langley R, Fidler IJ: Circulating monocytes expressing CD31: implications for acute and chronic angiogenesis. Am J Pathol 2009, 174:1972-1980

45. Rajantie I, IImonen M, Alminaite A, Ozerdem U, Alitalo K, Salven P Adult bone marrow-derived cells recruited during angiogenesis comprise precursors for periendothelial vascular mural cells. Blood 2004, 104:2084-2086

46. Song S, Ewald AJ, Stallcup W, Werb Z, Bergers G: PDGFRbeta+ perivascular progenitor cells in tumours regulate pericyte differentiation and vascular survival. Nat Cell Biol 2005, 7:870-879

47. Beckermann BM, Kallifatidis G, Groth A, Frommhold D, Apel A Mattern J, Salnikov AV, Moldenhauer G, Wagner W, Diehlmann A, Saffrich R, Schubert M, Ho AD, Giese N, Buchler MW, Friess $H$, Buchler P. Herr I: VEGF expression by mesenchymal stem cells contributes to angiogenesis in pancreatic carcinoma. $\mathrm{Br} \mathrm{J}$ Cancer 2008, 99:622-631

48. Sun B, Zhang S, Ni C, Zhang D, Liu Y, Zhang W, Zhao X, Zhao C, Sh M: Correlation between melanoma angiogenesis and the mesenchymal stem cells and endothelial progenitor cells derived from bone marrow. Stem Cells Dev 2005, 14:292-298

49. Bertolini F, Shaked Y, Mancuso P, Kerbel RS: The multifaceted circulating endothelial cell in cancer: towards marker and target identification. Nat Rev Cancer 2006, 6:835-845

50. Hirschi KK, Ingram DA, Yoder MC: Assessing identity, phenotype, and fate of endothelial progenitor cells. Arterioscler Thromb Vasc Biol 2008, 28:1584-1595

51. Horrevoets AJ: Angiogenic monocytes: another colorful blow to endothelial progenitors. Am J Pathol 2009, 174:1594-1596

52. Yoder MC, Ingram DA: Endothelial progenitor cell: ongoing controversy for defining these cells and their role in neoangiogenesis in the murine system. Curr Opin Hematol 2009, 16:269-273

53. Gao D, Nolan D, McDonnell K, Vahdat L, Benezra R, Altorki N, Mittal $\mathrm{V}$ : Bone marrow-derived endothelial progenitor cells contribute to the angiogenic switch in tumor growth and metastatic progression. Biochim Biophys Acta 2009, 1796:33-40

54. Lewis JS, Landers RJ, Underwood JC, Harris AL, Lewis CE: Expression of vascular endothelial growth factor by macrophages is upregulated in poorly vascularized areas of breast carcinomas. J Pathol 2000, 192:150-158

55. Coussens LM, Tinkle CL, Hanahan D, Werb Z: MMP-9 supplied by bone marrow-derived cells contributes to skin carcinogenesis. Cell 2000, 103:481-490

56. Giraudo E, Inoue M, Hanahan D: An amino-bisphosphonate targets MMP-9-expressing macrophages and angiogenesis to impair cervical carcinogenesis. J Clin Invest 2004, 114:623-633

57. Luo Y, Zhou H, Krueger J, Kaplan C, Lee SH, Dolman C, Markowitz D, Wu W, Liu C, Reisfeld RA, Xiang R: Targeting tumor-associated macrophages as a novel strategy against breast cancer. J Clin Invest 2006, 116:2132-2141

58. Fischer C, Jonckx B, Mazzone M, Zacchigna S, Loges S, Pattarini L, Chorianopoulos E, Liesenborghs L, Koch M, De Mol M, Autiero M Wyns S, Plaisance S, Moons L, van Rooijen N. Giacca M, Stassen JM, Dewerchin M, Collen D, Carmeliet P: Anti-PIGF inhibits growth of VEGF(R)-inhibitor-resistant tumors without affecting healthy vessels, Cell 2007, 131:463-475

59. Wyckoff J, Wang W, Lin EY, Wang Y, Pixley F, Stanley ER, Graf T, Pollard JW, Segall J, Condeelis J: A paracrine loop between tumor cells and macrophages is required for tumor cell migration in mammary tumors. Cancer Res 2004, 64:7022-7029 
60. Stockmann C, Doedens A, Weidemann A, Zhang N, Takeda N, Greenberg JI, Cheresh DA, Johnson RS: Deletion of vascular endothelial growth factor in myeloid cells accelerates tumorigenesis. Nature 2008, 456:814-818

61. Jain RK: Normalization of tumor vasculature: an emerging concept in antiangiogenic therapy. Science 2005, 307:58-62

62. Egeblad M, Ewald AJ, Askautrud HA, Truitt ML, Welm BE, Bainbridge E, Peeters G, Krummel MF, Werb Z: Visualizing stromal cell dynamics in different tumor microenvironments by spinning disk confocal microscopy. Dis Model Mech 2008, 1:155-167

63. Hoffman RM, Yang M: Color-coded fluorescence imaging of tumorhost interactions. Nat Protoc 2006, 1:928-935

64. Qian B, Deng Y, Im JH, Muschel RJ, Zou Y, Li J, Lang RA, Pollard JW: A distinct macrophage population mediates metastatic breast cancer cell extravasation, establishment and growth. PLoS One 2009, 4:e6562

65. Passlick B, Flieger D, Ziegler-Heitbrock HW: Identification and characterization of a novel monocyte subpopulation in human peripheral blood. Blood 1989, 74:2527-2534

66. Augustin HG, Koh GY, Thurston G, Alitalo K: Control of vascular morphogenesis and homeostasis through the angiopoietin-Tie system. Nat Rev Mol Cell Biol 2009, 10:165-177

67. Bergers G, Brekken R, McMahon G, Vu TH, Itoh T, Tamaki K, Tanzawa K, Thorpe P, Itohara S, Werb Z, Hanahan D: Matrix metalloproteinase-9 triggers the angiogenic switch during carcinogenesis. Nat Cell Biol 2000, 2:737-744

68. Fridlender ZG, Sun J, Kim S, Kapoor V, Cheng G, Ling L, Worthen GS, Albelda SM: Polarization of tumor-associated neutrophil phenotype by TGF-beta: "N1" versus "N2" TAN. Cancer Cell 2009, 16:183-194

69. Gabrilovich DI, Nagaraj S: Myeloid-derived suppressor cells as regulators of the immune system. Nat Rev Immunol 2009, 9:162-174

70. Movahedi K, Guilliams M, Van den Bossche J, Van den Bergh R, Gysemans C, Beschin A, De Baetselier P, Van Ginderachter JA: Identification of discrete tumor-induced myeloid-derived suppressor cell subpopulations with distinct T cell-suppressive activity. Blood 2008, 111:4233-4244

71. Umemura N, Saio M, Suwa T, Kitoh Y, Bai J, Nonaka K, Ouyang GF, Okada M, Balazs M, Adany R, Shibata T, Takami T: Tumor-infiltrating myeloid-derived suppressor cells are pleiotropic-inflamed monocytes/macrophages that bear M1- and M2-type characteristics. J Leukoc Biol 2008, 83:1136-1144

72. Sawanobori Y, Ueha S, Kurachi M, Shimaoka T, Talmadge JE, Abe J, Shono Y, Kitabatake M, Kakimi K, Mukaida N, Matsushima K: Chemokine-mediated rapid turnover of myeloid-derived suppressor cells in tumor-bearing mice. Blood 2008, 111:5457-5466

73. Youn JI, Nagaraj S, Collazo M, Gabrilovich DI: Subsets of myeloidderived suppressor cells in tumor-bearing mice. J Immunol 2008, 181:5791-5802

74. Crivellato E, Nico B, Ribatti D: Mast cells and tumour angiogenesis: new insight from experimental carcinogenesis. Cancer Lett 2008, 269:1-6

75. Starkey JR, Crowle PK, Taubenberger S: Mast-cell-deficient WNV mice exhibit a decreased rate of tumor angiogenesis. Int $\mathrm{J}$ Cancer 1988, 42:48-52

76. Gounaris E, Erdman SE, Restaino C, Gurish MF, Friend DS, Gounari F, Lee DM, Zhang G, Glickman JN, Shin K, Rao VP, Poutahidis T, Weissleder R, McNagny KM, Khazaie K: Mast cells are an essential hematopoietic component for polyp development. Proc Natl Acad Sci USA 2007, 104:19977-19982

77. Clarke S, Gordon S: Myeloid-specific gene expression. J Leukoc Biol 1998, 63:153-168

78. Gao D, Nolan DJ, Mellick AS, Bambino K, McDonnell K, Mittal V: Endothelial progenitor cells control the angiogenic switch in mouse lung metastasis. Science 2008, 319:195-198

79. Ruzinova MB, Schoer RA, Gerald W, Egan JE, Pandolfi PP, Rafii S, Manova K, Mittal V, Benezra R: Effect of angiogenesis inhibition by Id loss and the contribution of bone-marrow-derived endothelial cells in spontaneous murine tumors. Cancer Cell 2003, 4:277-289

80. Grunewald M, Avraham I, Dor Y, Bachar-Lustig E, Itin A, Jung S, Chimenti S, Landsman L, Abramovitch R, Keshet E: VEGF-induced adult neovascularization: recruitment, retention, and role of accessory cells. Cell 2006, 124:175-189

81. Petit I, Jin D, Rafii S: The SDF-1-CXCR4 signaling pathway: a mo- lecular hub modulating neo-angiogenesis. Trends Immunol 2007 28:299-307

82. Chan DA, Kawahara TL, Sutphin PD, Chang HY, Chi JT, Giaccia AJ: Tumor vasculature is regulated by PHD2-mediated angiogenesis and bone marrow-derived cell recruitment. Cancer Cell 2009, 15:527-538

83. De Palma M, Naldini L: Tie2-expressing monocytes (TEMs): Novel targets and vehicles of anticancer therapy? Biochim Biophys Acta 2009, 1796:5-10

84. McFarland HI, Nahill SR, Maciaszek JW, Welsh RM: CD11b (Mac-1): a marker for CD8+ cytotoxic T cell activation and memory in virus infection. J Immunol 1992, 149:1326-1333

85. McKnight AJ, Macfarlane AJ, Dri P, Turley L, Willis AC, Gordon S Molecular cloning of $F 4 / 80$, a murine macrophage-restricted cell surface glycoprotein with homology to the G-protein-linked transmembrane 7 hormone receptor family. J Biol Chem 1996, 271:486-489

86. Hirsch S, Gordon S: The use and limitation of monoclonal antibodies against mononuclear phagocytes. Immunobiology 1982 161:298-307

87. Zhang J, Kawashima N, Suda H, Nakano Y, Takano Y, Azuma M: The existence of $\mathrm{CD} 11 \mathrm{C}+$ sentinel and F4/80+ interstitial dendritic cells in dental pulp and their dynamics and functional properties. Int Immunol 2006, 18:1375-1384

88. McGarry MP, Stewart CC: Murine eosinophil granulocytes bind the murine macrophage-monocyte specific monoclonal antibody F4/80 J Leukoc Biol 1991, 50:471-478

89. Daley JM, Thomay AA, Connolly MD, Reichner JS, Albina JE: Use of Ly6G-specific monoclonal antibody to deplete neutrophils in mice. J Leukoc Biol 2008, 83:64-70

90. Barleon B, Sozzani S, Zhou D, Weich HA, Mantovani A, Marme D: Migration of human monocytes in response to vascular endothelia growth factor (VEGF) is mediated via the VEGF receptor flt-1. Blood 1996, 87:3336-3343

91. Kerber M, Reiss Y, Wickersheim A, Jugold M, Kiessling F, Heil M Tchaikovski V, Waltenberger J, Shibuya M, Plate KH, Machein MR: Flt-1 signaling in macrophages promotes glioma growth in vivo. Cancer Res 2008, 68:7342-7351

92. Sawano A, Iwai S, Sakurai Y, Ito M, Shitara K, Nakahata T, Shibuya M: Flt-1, vascular endothelial growth factor receptor 1 , is a novel cell surface marker for the lineage of monocyte-macrophages in humans. Blood 2001, 97:785-791

93. Feistritzer C, Mosheimer BA, Sturn DH, Bijuklic K, Patsch JR, Wiedermann CJ: Expression and function of the angiopoietin receptor Tie-2 in human eosinophils. J Allergy Clin Immunol 2004 114:1077-1084

94. Nakayama T, Yao L, Tosato G: Mast cell-derived angiopoietin-1 plays a critical role in the growth of plasma cell tumors. J Clin Invest 2004, 114:1317-1325

95. Baeten $\mathrm{Cl}$, Castermans K, Hillen HF, Griffioen AW: Proliferating endothelial cells and leukocyte infiltration as prognostic markers in colorectal cancer. Clin Gastroenterol Hepatol 2006, 4:1351-1357

96. Bouma-ter Steege JC, Baeten Cl, Thijssen VL, Satijn SA, Verhoeven IC, Hillen HF, Wagstaff J, Griffioen AW: Angiogenic profile of breast carcinoma determines leukocyte infiltration. Clin Cancer Res 2004, 10:7171-7178

97. Barbera-Guillem E, Nyhus JK, Wolford CC, Friece CR, Sampsel JW Vascular endothelial growth factor secretion by tumor-infiltrating macrophages essentially supports tumor angiogenesis, and IgG immune complexes potentiate the process. Cancer Res 2002 62:7042-7049

98. Hamann J, Koning N, Pouwels W, Ulfman LH, van Eijk M, Stacey M Lin HH, Gordon S, Kwakkenbos MJ: EMR1, the human homolog of $\mathrm{F} 4 / 80$, is an eosinophil-specific receptor. Eur $\mathrm{J}$ Immunol 2007 $37: 2797-2802$

99. Leek RD, Lewis CE, Whitehouse R, Greenall M, Clarke J, Harris AL: Association of macrophage infiltration with angiogenesis and prognosis in invasive breast carcinoma. Cancer Res 1996, 56:4625-4629

100. Yamaguchi R, Yano H, Nakashima Y, Ogasawara S, Higaki K, Akiba $\mathrm{J}$, Hicklin DJ, Kojiro M: Expression and localization of vascular endothelial growth factor receptors in human hepatocellular carcinoma and non-HCC tissues. Oncol Rep 2000, 7:725-729

101. Ruan J, Hyjek E, Kermani P, Christos PJ, Hooper AT, Coleman M, Hempstead B, Leonard JP, Chadburn A, Rafii S: Magnitude of 
stromal hemangiogenesis correlates with histologic subtype of nonHodgkin's lymphoma. Clin Cancer Res 2006, 12:5622-5631

102. Rempel SA, Dudas S, Ge S, Gutierrez JA: Identification and localization of the cytokine SDF1 and its receptor. CXC chemokine receptor 4, to regions of necrosis and angiogenesis in human glioblastoma. Clin Cancer Res 2000, 6:102-111

103. Freedman RS, Ma Q, Wang E, Gallardo ST, Gordon IO, Shin JW, Jin P, Stroncek D, Marincola FM: Migration deficit in monocyte-macrophages in human ovarian cancer. Cancer Immunol Immunother 2008, 57:635-645
104. Lemieux C, Maliba R, Favier J, Theoret JF, Merhi Y, Sirois MG: Angiopoietins can directly activate endothelial cells and neutrophils to promote proinflammatory responses. Blood 2005, 105: 1523-1530

105. De Palma M, Mazzieri R, Politi LS, Pucci F, Zonari E, Sitia G, Mazzoleni S, Moi D, Venneri MA, Indraccolo S, Falini A, Guidotti LG Galli R, Naldini L: Tumor-targeted interferon-alpha delivery by Tie2 expressing monocytes inhibits tumor growth and metastasis. Cancer Cell 2008, 14:299-311 